\title{
OTROS MUNDOS, OTRAS GEOGRAFÍAS. LOS PAISAJES RESIDUALES
}

\section{Other Worlds. Another Geography. Residual Landscapes}

Prof. Dr. Joan Nogué

Universitat de Girona

Luís Companys, 27, 2º $1^{\text {a }} 17820$ - Banyoles (SPAIN)

Tel: 972418715 - joan.nogue@udg.edu

\author{
$a a \boldsymbol{a} a a$
}

\begin{abstract}
Resumo
O autor faz uma reflexão sobre o papel da pesquisa geográfica contemporânea. Defende as condições singulares da geografía e do geógrafo perante as demais ciências e profissionais, dados a lhes permitir compreensão da complexidade do mundo na atualidade. Em discussão mais aprofundada se pauta na paisagem como um dado contruido socialmente., porém, não vista, as denominadas 'paisagens residuais'. Soimente nestes termos acredita que podemos a outra paisagens e outras geografias.
\end{abstract}

Palavras-chave: Paisagem residual, geografia, identidades territoriais

\begin{abstract}
The author reflects upon contemporary geographical research. He defends that both geography and the geographer hold specific conditions in relation to other sciences and professionals that allow them to grasp the complexity of the world at the present time. For further discussion, he bases his conviction on the landscape. He focuses specifically on those landscapes that have been socially built, but which are not seen. Such sceneries, known as residual landscapes, are used as examples to illustrate other worlds and other geographies

Key words: Residual landscape, territory, territorial identities.

\section{Resumen}

Aunque no seamos conscientes de ello, aunque no los veamos ni los miremos, lo cierto es que nos movemos cotidianamente entre paisajes incógnitos y territorios ocultos, entre geografías invisibles sólo en apariencia. Las geografías de la invisibilidad marcan nuestras coordenadas espaciales y temporales, nuestros espacios existenciales, tanto como las geografías cartesianas, visibles y cartografiables propias de las lógicas territoriales hegemónicas. Los paisajes se construyen socialmente y es por ello que muchas veces sólo vemos los paisajes que 'deseamos' ver, es decir aquellos que no cuestionan nuestra idea de paisaje. Este es exactamente el caso de lo que yo denomino 'paisajes residuales', que, a modo de ejemplo, he escogido para esta conferencia. Para acceder a los mismos hay que ser capaz de 'mirar más allá', de no fiarse de las apariencias, de no confundir lo visible con lo real. Sólo así podremos acceder a los ‘otros' paisajes,a las ‘otras' geografías.
\end{abstract}

Palabras clave: Paisage residuale, geografía, identidade territorial.

\section{aaCaa}




\section{INTRODUÇÃO}

El tema de este encuentro nacional de geografía es la investigación y la producción geográficas en la actualidad. Ante un tema central de esta amplitud yo tenía dos opciones: o preparar una especie de sinopsis general sobre las principales líneas y temas de investigación existentes en estos momentos o reflexionar más bien sobre la actitud que yo considero fundamental ante toda investigación geográfica a partir de un ejemplo concreto. He optado por esta segunda opción, porque me parece que la primera queda sobradamente reflejada en las ponencias y mesas redondas que ustedes tendrán a lo largo de los próximos días. Poca cosa más les podría añadir yo. Me parece más oportuna y adecuada una reflexión personal, en voz alta, sobre el papel de la investigación geográfica en la contemporaneidad.

Déjenme confesarles de entrada que cada vez tengo más claro que la geografía es una disciplina idónea para comprender la complejidad del mundo contemporáneo. Su visión holística, global, multifactorial, a caballo entre las ciencias humanas y sociales y las ciencias naturales, la sitúa en una posición privilegiada para entender la lógica del laberinto en el que se ha convertido nuestro mundo. Otra cosa es que los geógrafos y geógrafas sepamos aprovechar esta posición privilegiada a la que me refería. Y me temo que no siempre es así. A veces nos encasillamos, nos aferramos y nos apoltronamos en exceso a unos determinados temas, conceptos y métodos, y ello nos conduce a una visión limitada, unidireccional, reduccionista de la realidad que nos rodea. Debemos aprender a superar estas limitaciones y ser capaces de formular nuevos paradigmas, de descubrir nuevas territorialidades. La realidad está constituida, a la vez, por presencias y ausencias, por elementos que se manifiestan y otros que se esconden, pero que siguen estando allí. La realidad no es sólo lo que se ve. Lo visible no se puede identificar con lo real, y al revés. Hay que aprender a mirar lo que no se ve, como aquellos historiadores del arte que son capaces de intuir que debajo de una pintura visible hay otra invisible, en general más interesante que la primera, como ha sucedido tantas y tantas veces. El geógrafo y la geógrafa de nuestros días deben convertirse en zahoríes del espacio geográfico, del territorio, del paisaje.

Para llegar a ello es imprescindible adoptar una actitud un tanto atrevida, arriesgada, aventurera y, sobre todo, muy curiosa. Una actitud abierta a todas las vías de acceso al conocimiento, incluidas las emocionales. No deberíamos olvidar que la vida es, en esencia y a la vez, espacial y emocional. Interactuamos emocionalmente y de manera continua con los lugares, a los que imbuimos de significados que retornan a nosotros a través de las emociones que nos despiertan. La memoria individual y colectiva, así como la imaginación, más que temporales, son espaciales. Las categorías geográficas básicas que se aprenden en la escuela, o las que utilizamos en nuestra vida cotidiana, conllevan asociaciones emocionales. Experimentamos emociones específicas en distintos contextos geográficos y 'vivimos' emocionalmente los paisajes porque éstos no son sólo materialidades tangibles, sino también construcciones sociales y culturales impregnadas de un denso contenido intangible a menudo solamente accesible a través del universo de las emociones. La geografía como disciplina no debería intentar despojarse de su dimensión emocional por la sencilla razón de que las topografías de la vida cotidiana están demasiado impregnadas de emoción y sentimiento y nuestros tratados de geografía no dejan de ser, en el fondo, una especie de psicogeografías personales y sociales. En estos tratados los lugares parecen inmóviles, pero no lo son, porque viajan con nosotros a través de las emociones, con lo que, debajo de nuestra cartesiana cartografía, lo que de verdad subyace es una cartografía emotiva.

Sólo -repito- con una actitud abierta y constantemente autocrítica accederemos a las 'otras geografías', esto es a los paisajes incógnitos y los territorios ocultos de las grandes metrópolis, a los nuevos espacios disidentes, al cuerpo humano como objeto y sujeto geográfico, a la dimensión espacial de las relaciones de género, a las geografías de la exclusión, a las geografías de la evasión, a las geografías emocionales generadas por las diásporas, el exilio y la emigración, a los paisajes sensoriales no visuales inducidos por el resto de nuestros sentidos o, sin ir más lejos, al fundamental 
y a la vez complejo proceso a través del cual los seres humanos imbuimos de significado al espacio geográfico y creamos lugares. Sólo así seremos capaces de entender la principal paradoja espacial de nuestro mundo: hoy, cuando parecía que la Tierra había sido finalmente explorada y cartografiada en su totalidad y hasta el más mínimo detalle, reaparecen nuevas "tierras incógnitas". En nuestros días, ante los ojos -o, mejor dicho, ante las lentes- de los más sofisticados sistemas de teledetección y de información geográfica, están apareciendo de nuevo espacios en blanco en nuestros mapas, con unos límites imprecisos y cambiantes, difusos, difíciles de percibir y, aún más, de cartografiar. Nuestros mapas, en efecto, se han llenado de nuevo de tierras desconocidas, de regiones que se alejan, que se 'descartografían' y se vuelven opacas. Hacia estos nuevos espacios en blanco en nuestros mapas, hacia estas otras geografías, deben orientarse las nuevas 'expediciones' geográficas.

Y para conseguirlo es imprescindible no sentirse atado a unas supuestas fronteras temáticas, metodológicas e instrumentales. Un ejemplo: lo invisible, lo intangible y lo efímero no han constituido nunca el corazón central de las disciplinas que piensan, ordenan, intervienen y transforman el territorio y sus paisajes. Las descripciones y análisis territoriales suelen ser visuales, de base empírica, cartesianas, centradas en los tangibles y poco interesadas por la efimeralidad y la fugacidad, y sí mucho más por el tiempo de media y larga duración. No estoy insinuando que tengan que pasar a ser el corazón de dichas disciplinas: simplemente estoy constatando que han sido, son y probablemente seguirán siendo marginales en su teoría y en su práctica. Y, con todo, no puedo dejar de preguntarme si esta marginalidad excesiva no es una carencia, un punto débil, a la hora de interpretar y entender las sociedades contemporáneas y los paisajes que éstos crean, porque resulta que, por paradójico que pueda parecer, la invisibilidad, la intangibilidad y la efimeralidad están cada vez más presentes en el mundo que nos rodea.

Aunque no seamos conscientes de ello, aunque no los veamos ni los miremos, lo cierto es que nos movemos cotidianamente entre paisajes incógnitos y territorios ocultos, entre geografías invisibles sólo en apariencia. Las geografías de la invisibilidad -aquellas geografías que están sin estar- marcan nuestras coordenadas espaciales y temporales, nuestros espacios existenciales, puede que no más, pero sí tanto como las geografías cartesianas, visibles y cartografiables propias de las lógicas territoriales hegemónicas. Conviene no olvidar que los paisajes (los visibles y los invisibles) se construyen socialmente y que la 'mirada' del paisaje es extraordinariamente compleja y en ella interactúan muchas identidades sociales diferentes. En efecto, muchas veces sólo vemos los paisajes que 'deseamos' ver, es decir aquellos que no cuestionan nuestra idea de paisaje, construida socialmente. Este es exactamente el caso de lo que yo denomino 'paisajes residuales' que, simplemente a modo de ejemplo, he escogido para esta conferencia.

\section{PAISAJES DEL ABANDONO}

A mi entender, en las tipologías de paisaje propias de las sociedades capitalistas habría que incluir una nueva categoría: los paisajes del deterioro, del deshecho, del rechazo,...en definitiva, los paisajes residuales, aludiendo al título de esta contribución, y otorgando al término 'residual' tanto la acepción vinculada al propio residuo como objeto como la connotación relativa a aquello 'secundario', 'sobrante', 'superfluo' y, por tanto, banal, irrelevante, prácticamente invisible. El sistema de producción y de consumo hegemónico en el mundo contemporáneo desde hace decenios genera espacios-basura que conforman, a su vez, auténticos paisajes-basura, algunos de los cuales, por cierto, son reciclados, reaprovechados, como a veces hacemos con los deshechos domésticos.

Uno de los efectos más notables y menos estudiados de los actuales procesos de industrialización, metropolitanización y urbanización difusa y dispersa por el territorio es el surgimiento de infinidad de espacios vacíos, desocupados, aparentemente libres; espacios sin ninguna función clara en el nuevo entramado territorial. Aparecen como tierras de nadie, territorios sin rumbo y sin personalidad, despojados como están de su carácter primigenio, de su razón de ser en un territorio que ha dejado de existir. Son espacios indeterminados, de límites imprecisos, de usos inciertos, 
expectantes, en ocasiones híbridos entre lo que han dejado de ser y lo que no se sabe si serán; extraños lugares que parecen condenados a un destierro desde el que contemplan, impasibles, los dinámicos circuitos de producción y consumo de los que han sido apartados y a los que algunos -no todos- volverán algún día. Son paisajes-basura, paisajes en ruina.

Estos paisajes del deshecho se hallan dispersos por todo el territorio, pero se multiplican en las periferias urbanas, entre y a los lados de autopistas, autovías y cinturones orbitales. Ahí se alternan sin solución de continuidad terrenos intersticiales yermos y abandonados, viejos polígonos industriales, canteras, depósitos de escombros, vertederos controlados e incontrolados, cementerios de coches, almacenes precarios, antiguas y nuevas líneas de alta tensión, restos de carteles publicitarios, descampados intermitentes, edificios e infraestructuras obsoletas, frágiles y efímeros cobertizos en desuso, naves comerciales de aspecto más bien cutre, fábricas que hace tiempo dejaron de funcionar, talleres mecánicos que se quedaron vacíos, chatarrerías con chatarra pero sin chatarreros, estaciones de ferrocarril cerradas a cal y canto, vías de tren que no llevan a ninguna parte, chimeneas que no echan humo, torres del tendido eléctrico medio derruidas, carreteras por las que ya no se circula, puentes por los que nadie transita porque no llevan a ninguna parte.... La lista, interminable, configura auténticos paesaggi del rifiuto, como dicen los italianos. La legibilidad semiótica de este tipo de paisajes es compleja. No es nada fácil la descodificación de sus símbolos. No es fácil integrar en una lógica discursiva clara y comprensible los territorios fracturados y desdibujados de estos paisajes que a veces parecen itinerantes, nómadas, no porque se muevan, sino porque son repetitivos, porque son parecidos en todas partes.

En estos paisajes indecisos y olvidados campan a su aire las 'ruinas sin esplendor', como yo denomino a este sinfín de edificios e infraestructuras obsoletas, sin ningún valor arquitectónico ni patrimonial reconocido Es justamente su escaso o nulo valor lo que ha permitido a estas peculiares ruinas pasar inadvertidas, casi invisibles. Al haber perdido la función original que justificó la construcción de aquello de lo que son memoria y al no haber adquirido otra a cambio, como suele ser habitual en edificios e infraestructuras rescatadas por la arqueología industrial, han dejado de existir desde el punto de vista funcional, pero no físico, porque siguen enquistadas en el mismo lugar, aunque nunca sabremos con certeza hasta cuándo. Este tipo de ruinas responde a una estética de la desolación y también de la invisibilidad: son poco visibles no porque no se vean, sino porque no las miramos. Están en el territorio sin estar, como convidados de piedra.

No tiene sentido conservarlas porque, efectivamente, no poseen el más mínimo valor que pueda justificar inversión alguna, sea pública o privada. Son, además, un estorbo en muchos sentidos, por lo que suelen ser las primeras candidatas a la demolición cuando se interviene en el paisaje en el marco de proyectos urbanísticos y territoriales de rehabilitación y adecentamiento del entorno, ya sea rural o urbano. Están condenadas de antemano y de manera irremisible a desaparecer. Y, sin embargo, al contemplarlas, algo nos dice que deberíamos meditar un segundo antes de echarlas abajo; que deberíamos ser capaces, al menos, de observarlas y 'leerlas' antes del derribo, en tanto que testimonios mudos de un pasado reciente y a veces de un presente fugaz. El imparable proceso de 'destrucción creativa' que el economista Joseph Schumpeter vinculaba a la esencia del capitalismo industrial debería, a veces, congelarse, aunque sólo fuese momentáneamente.

Más que sus estructuras arquitectónicas, son los pequeños detalles perdidos en su interior los que nos hablan de quienes consumieron ahí buena parte de sus vidas: una silla donde alguien se sentó durante años, un guante que encubrió una mano, unos servicios rotos y destartalados en los que un obrero se refugió a ratos para escapar de la cadena de montaje, una llave inglesa que dio mil vueltas a la tuerca, una frase escrita en la pared por una mano anónima, papeles de un viejo archivo metálico esparcidos por el suelo, los restos de un coche que quizá viajó por medio país y cuya radio se quedó en una frecuencia concreta, la última que escuchó el último individuo que se bajó del auto. Estos objetos irrelevantes, estos ínfimos detalles nos remiten a actos cotidianos que se dieron en un momento y lugar concretos, por parte de alguien que nunca conoceremos. He ahí la fugacidad no inmortalizada (porque, a no tardar, va a desaparecer de manera definitiva), pero sí 
suspendida momentáneamente en el tiempo y en el espacio y de la que nosotros somos, por puro azar, espectadores privilegiados. Una fugacidad que hasta cierto punto podemos captar a través de la fotografía, pero sólo hasta cierto punto, porque ésta nunca podrá capturar en su totalidad la vida que albergaron estos espacios y tiempos, que están hechos también de sonidos -y, más aún, de silencios-, de olores, de texturas que sólo podemos experimentar a través del tacto; de sensaciones difíciles de describir, pero muy potentes y sugerentes.

Las ruinas con esplendor, las ruinas reconocidas por todos como tales, integradas de lleno en el orden espacial legitimado por el poder, nos transmiten sublimidad, nobleza y belleza con mayúsculas. Las ruinas aquí descritas, diáfana expresión del desorden espacial inherente a la marginalidad territorial del sistema y representantes supremas de los paisajes residuales y del deshecho, sólo pueden aspirar a su pequeño instante de gloria en el preciso momento en el que nos detenemos a contemplarlas, a sentirlas. Es entonces cuando despiertan en nosotros, aunque sea en pequeñas dosis, nostalgia y melancolía. La melancolía del ocaso, la tristeza del abandono.

\section{SKY(BACK)LINE}

Estos paisajes del deshecho que acabamos de describir se ocultan cada vez más a nuestra mirada. Las estrategias de cosmética urbana tienden desde hace años a la ocultación de los paisajes-basura, a menos que no se hayan reciclado a través de proyectos de restauración paisajística, lo cual suele estar reservado a paisajes con cierto valor patrimonial, reconocidos como tales por la arqueología industrial. Si no es así, estos entornos degradados y abandonados están cada vez menos a la vista. Sin embargo, asistimos en este punto a una cierta paradoja creada por las propias contradicciones del sistema. Resulta que estos procesos de ocultación se han visto en buena medida truncados por el trazado de las nuevas vías de circunvalación de los núcleos urbanos, generados por la expansión urbanística y el incremento del tráfico rodado. Es curioso, pero parecería como si, de pronto, de la noche a la mañana, pueblos, villas y ciudades hubieran decidido darnos la espalda para mirar hacia otro lado; como si hubieran dado la vuelta sobre sí mismos y dejaran de mirarnos de frente. Parece como si nos hubiéramos metido en su patio trasero sin permiso y hubiéramos pillado a decenas de núcleos de población con la casa por barrer. Estos nuevos trazados que sortean el interior del casco urbano discurren por detrás, por los espacios aún libres de las periferias urbanas. Se meten por aquellos espacios hasta ahora más íntimos y escamoteados a la vista; espacios en los que uno siempre espera encontrar -y encuentra- un cierto caos y desorden y en los que se acumulan sin ton ni son los más diversos artefactos, en su mayoría en desuso. Es un paisaje residual, pero en este caso con aire de rebotica.

Para miles de automovilistas, este detrás se convierte en delante, es decir en la nueva y auténtica fachada del núcleo urbano que se ha circunvalado. La inmensa mayoría de estos ciudadanos no pondrán jamás un pie en el centro urbano y, por ello mismo, no tendrán ocasión de contemplar la que hasta ahora había sido la fachada principal del núcleo en cuestión, esto es aquella imagen percibida y vivida durante generaciones; una imagen que conformó en su momento el estereotipo paisajístico del lugar y que penetró en el imaginario colectivo de la ciudadanía. Será interesante analizar a partir de ahora qué va a suceder con estos nuevos espacios y los paisajes más bien desolados que los caracterizan, sobre todo en aquellos casos en los que, por diversas razones, interesa -y mucho- que el conductor se decida a salir del cinturón orbital y a visitar el lugar. Por de pronto, los especialistas en citymarketing y en landscape branding se han limitado a 'trasladar' a las nuevas rondas en forma de grandes carteles publicitarios el estereotipo conocido y consumido y el skyline tradicional, aunque lo que el automovilista perciba en la realidad no tenga nada que ver con éste, sino más bien con el sky(back)line.

No es sólo el trazado de estos ejes de circunvalación por las periferias urbanas lo que ha dado la vuelta al calcetín. Algo parecido sucede con las nuevas líneas ferroviarias, tanto las convencionales como las recorridas por trenes de alta velocidad. Nuevas perspectivas, nuevos encuadres, 
nuevos puntos de vista surgen de la nada. También en este caso miles de viajeros van a percibir de otra manera y desde otro ángulo el mismo lugar en el que durante años han vivido o por el que simplemente han transitado. Tendrán que rehacer sus imaginarios paisajísticos momentáneamente porque lo que realmente van a percibir durante un tiempo, mientras no se apliquen los consabidos proyectos paisajísticos de ocultación, van a ser paisajes residuales. Y algo parecido está sucediendo, al menos en Europa, con los nuevos aeropuertos low cost. Más y más ciudadanos europeos llegan a las grandes capitales por la 'puerta de detrás', esto es por aeropuertos de segunda categoría situados a un centenar de kilómetros del destino real. Los vuelos de bajo coste han quitado el polvo a pequeños aeropuertos anodinos y de aspecto fantasmagórico y banal que sirven como simple puerta de entrada a los verdaderos puntos de destino. Se 'aterriza' en los aeropuertos de Treviso y de Girona-Costa Brava, pero donde realmente se 'llega' es a Venecia y a Barcelona, respectivamente. No estamos asistiendo sólo a la emergencia de vuelos y aeropuertos low cost, sino también a la creación de paisajes low cost, muy propios de las nuevas trastiendas territoriales y muy cercanos a los paisajes residuales objeto de este texto.

Pero no nos engañemos: no vemos muchos de estos paisajes residuales simplemente porque nos los oculten, sino porque nuestra mirada no los detecta, aunque los vea. Como decía al principio, vemos los paisajes que 'deseamos' ver, es decir aquellos que no cuestionan nuestra idea de paisaje, construida socialmente. Buscamos en el paisaje aquellos modelos, aquellos patrones que se ajustan a los que tenemos en nuestro inconsciente colectivo, o que más se aproximan a ellos. Y, por eso, estos paisajes periféricos y fuertemente transformados, estos paisajes del deshecho, nos son invisibles, aunque los veamos. Cuando no entendemos un paisaje, no lo vemos: lo miramos, pero no lo vemos. Por eso, aunque no seamos conscientes de ello, aunque no los veamos ni los miremos, lo cierto es que nos movemos cotidianamente entre paisajes incógnitos y territorios ocultos, entre geografías invisibles sólo en apariencia. Definitivamente, las geografías de la invisibilidad y sus correspondientes paisajes ocultos -entre ellos los paisajes-basura- están aún por descubrir.

\section{LOS PAISAJES DE LA CRISIS}

Como saben bien, España está en una grave crisis económica, de la que no sé, sinceramente, cómo ni cuándo saldremos. Lo que sí sé es que esta crisis está generando nuevos paisajes residuales inimaginables hace tan sólo cinco años, y casi me atrevería a decir que únicos en el mundo. Me refiero al paisaje que está dejando detrás de sí la hecatombe inmobiliaria después de años de incontrolado desarrollo urbanístico. Si uno se pasea hoy por España con los ojos un poco abiertos no le costará demasiado descubrir los despojos urbanísticos y arquitectónicos de una crisis económica generada por unos pocos y sufrida por la inmensa mayoría de la población. La costa mediterránea se ha convertido en un palmeral de grúas petrificadas y en los alrededores de Madrid y provincias limítrofes se cuentan por decenas las urbanizaciones con sus descampados y desiertos viales por los que nadie transita. Si, una vez finalizadas, muchas de estas urbanizaciones suelen presentar un aspecto inhóspito y desangelado, en su estado actual de abandono y a medio construir, transmiten al observador una imagen fantasmagórica, estremecedora. En estos momentos España ofrece miles de escenarios a guionistas cinematográficos, a escritores y a ciudadanos que quieran conocer de primera mano cómo se crea un lugar sin alma. En sitios como éstos, cualquiera puede entender con suma rapidez lo que es el vacío existencial-espacial. En algunas de estas urbanizaciones los primeros matorrales ya acechan y los desnudos pilares de hormigón armado, sometidos a las inclemencias de unos cuantos cálidos veranos y fríos inviernos, van pasando del gris claro original a un gris cada vez más oscuro. Además, todas ellas ya forman parte de nuestro paisaje urbano cotidiano y empiezan a hacer mella en nuestra memoria, en nuestro imaginario colectivo. ¿Hasta cuándo permanecerán en el limbo? ¿Tardará mucho en aparecer el primer parque arqueológico español de la obra incompleta, el primer museo al aire libre del abandono? La explosión de la burbuja inmobiliaria ha tenido graves consecuencias económicas y sociales y está generando infinidad de territorios sin discurso y de paisajes sin imaginario que la geografía no puede pasar por alto. 


\section{PAISAJES DE FRONTERA}

Los paisajes residuales a los que aquí estamos haciendo referencia han proliferado de tal manera y en cualquier sitio que han contribuido a consolidar la imagen de una morfología paisajística general de carácter más bien híbrido, fragmentado. Así es: la estructura y morfología del paisaje contemporáneo se caracteriza por una alta fragmentación y límites imprecisos. El mapa de usos del suelo típico del paisaje tradicional se ha transformado radicalmente y ha derivado hacia una gran dispersión de usos y de cubiertas del suelo. La antigua delimitación zonal se ha desdibujado, se ha roto su compacidad y ha acabado por imponerse un paisaje mucho más complejo y, hasta cierto punto, discordante. Los bordes, las fronteras entre distintas configuraciones paisajísticas, que no hace muchos años podían cartografiarse con precisión casi milimétrica, se han difuminado y ensanchado hasta ocupar centenares de hectáreas, generando unos paisajes mestizos, en continuo estado de transición. Estamos asistiendo, en efecto, al surgimiento de paisajes híbridos, fracturados, inestables, precarios; paisajes en busca de nuevos imaginarios en unos territorios que, a su vez, partieron en busca de nuevos discursos.

He ahí el reto de la hibridación, siempre presente en los paisajes de frontera difusa, como son los paisajes de mutación intensa, los paisajes de la dispersión, los sprawlscapes, paisajes que ocupan amplias extensiones de territorio en forma de manchas de aceite y que transmiten una nueva concepción del espacio y del tiempo. La hibridación propia de las fronteras territoriales, de los paisajes periféricos caracterizados a menudo por su componente residual, nos plantea enormes retos urbanísticos, territoriales, ambientales y sociales, además de conceptuales. ¿Se está perdiendo en ellos el sentido del lugar? ¿Podemos seguir concibiendo el lugar como una categoría geográfica - y ontológica - 'pura', en el sentido de contener una supuesta y exclusiva homogeneidad y coherencia internas? ¿Cómo se articula hoy día, en estos paisajes de frontera, la milenaria asociación identidad-lugar-paisaje?

Los paisajes de frontera, en su mayoría paisajes del desecho y de la ruina, tienen la virtud de suscitarnos estas preguntas y, quizá precisamente por ello, nos seducen. Pienso, por otra parte, que esta seducción inherente al límite, a todo tipo de límites territoriales, aunque sean mentales e imaginarios, tiene mucho que ver con la seducción del umbral, de la idea del umbral. Sólo en el umbral puede uno sentirse simultáneamente actor y espectador, observador y observado y saborear la increíble experiencia de estar dentro y fuera a la vez. Los límites territoriales ejercen a menudo esta función de umbral entre dos entidades geográficas distintas. La mezcolanza e hibridez que los suele caracterizar, como resultado del encuentro entre dos entes geográficos diferenciados, confieren a dichos límites un carácter propio en relación con los territorios que delimitan. Hemos focalizado históricamente nuestra atención en el centro de los espacios delimitados, en el corazón de las regiones, pero hemos minusvalorado lo que sucedía en los límites, en el umbral, a menudo mucho más fascinante. El umbral nos atrae como la penumbra. En ésta se da una seductora combinación de claroscuros y de modulaciones lumínicas que genera un ambiente mucho más rico en sensaciones que el iluminado por unos radiantes y nítidos rayos de sol. De manera parecida, en el umbral, en el límite, asistimos a la generación de un nuevo tipo de lugar de carácter vago e impreciso, mixto y heterogéneo y, por ello mismo, mucho más sugestivo.

\section{RECICLAJE DE PAISAJES}

Sea como fuere, lo cierto es que centenares de hectáreas van sumándose año tras año a los paisajes residuales aquí analizados y, a pesar de ello, a nadie se le ocurre qué hacer con ellos. Y, sin embargo, y a pesar de todo lo dicho, son paisajes que contienen nuevos elementos sobre los que se podría pensar e imaginar. No me refiero tanto a la restauración (reciclaje) ya tan manida y conocida, consistente en convertir paisajes degradados con cierto valor patrimonial reconocido por la arqueología industrial en nuevos paisajes del ocio y la recreación. Hay por ahí decenas de casos de reciclaje de antiguos paisajes industriales en nuevos paisajes culturales, algunos demasiado en 
línea, desde mi punto de vista, con la filosofía que inspira los parques temáticos. Me refiero a otro tipo de reciclaje, de 'mirada', si se quiere.

De alguna forma, estos espacios se han convertido, sin quererlo, en espacios disidentes, de trasgresión, y es precisamente por este motivo - a pesar de su momentáneo anacronismo e incluso de su innegable cutrez- por lo que podemos aprender de los usos sociales que espontáneamente se les ha dado. Son, en cierto sentido, la última frontera y, por ello mismo, habría que actuar sobre ellos muy discretamente, a una cierta distancia. Son el negativo de la estructuración del territorio, por lo que no tiene sentido intervenir en ellos como lo haríamos con el resto del territorio, pero sí podríamos apostar por la experimentación de nuevos usos y cánones estéticos, en tanto que nuevos paisajes surgidos de la nada. ¿Por qué no pensar en dar a estos espacios obsoletos, abandonados, un uso social alternativo? Debería ser, sin duda, un uso fugaz, versátil, variable, que difícilmente se dará en el espacio estructurado, planificado, eficiente y productivo que los ha engendrado en forma de externalidades territoriales no previstas. Se trataría de conceder a estos espacios conformadores de los paisajes residuales un papel protagonista en el proyecto territorial y en la intervención urbanística. Se trataría de 'leerlos' de otra manera hasta llegar a entenderlos como agentes activos y no como simples espectadores mudos, pasivos, del proyecto territorial y urbanístico.

Habría que comenzar por rescatar dichos espacios del anonimato; hacerlos visibles, cartografiarlos. Nos daríamos cuenta de que son muy abundantes y de variadas dimensiones y de que no sólo están localizados en las periferias urbanas de las grandes metrópolis, sino también en el campo y en las ciudades medias y pequeñas e incluso en el propio centro del casco urbano. Tal vez, entonces, podríamos desarrollar algo así como la ley espacial del abandono, de la desestructuración del territorio. Habría, pues, que mapear, fotografiar, recorrer y, sobre todo, sentir estos paisajes olvidados para, así, ser capaces de hablar de ellos en tanto que sujetos y no como meros subproductos de los usos que los marginan; para ser capaces de reconvertirlos pero no tematizándolos, sino en el contexto de un replanteamiento global de nuestras relaciones con el entorno. Sí, hay que revolver en la basura, en los paisajes residuales, en los 'otros' paisajes, en las 'otras' geografías.

\section{CONSIDERAÇÕES FINAIS}

Vuelvo, para terminar, al inicio de mi intervención. Estoy firmemente convencido de que la geografía es hoy un saber más relevante y estratégico que nunca y de que ostenta una posición privilegiada para entender la lógica de este cada vez más complejo mundo. Pero, para ello, la investigación geográfica debe ser capaz de 'mirar más allá', de no fiarse de las apariencias, de no confundir lo visible con lo real. No debe tener miedo a volar, a usar la imaginación, a formular atrevidas hipótesis, a servirse incluso de la emoción, si ello es preciso.

\section{REFERÊNCIAS BIBLIOGRÁFICAS}

NOGUÉ, J.; PUIGBERT, L.; BRETCHA, G. Indicadors de paisatge. Reptes i perspectives. Barcelona: Observatori del Paisatge de Catalunya, 2009.

NOGUÉ, J.; PUIGBERT, L.; BRETCHA, G. Ordenació i gestió del paisatge a Europa. Barcelona: Observatori del Paisatge de Catalunya, 2009.

NOGUÉ, J. Entre paisajes. Barcelona: Àmbit. Traducció italiana a l'editorial Franco Angeli amb el títol: Altri paesaggi, 2010.

NOGUÉ, Joan; ROMERO, Joan (orgs.) Las otras geografias. València: Tirant lo Blanch, 2007. 